\title{
An Examination of the Drivers of E-Marketing Capability in the Digital Age: An Abstract
}

\section{Xia Liu}

\begin{abstract}
This paper aims to find out how marketing can play a more strategic role in helping firms improve performance in the Digital Age. Particularly, this paper investigates the drivers of e-Marketing capability and the impact of e-Marketing capability. This research studies how IT capability, marketing, and IT cross-functional collaboration and leadership emphasis can impact e-Marketing capability and thus improve customer relationship management and new product diffusion. In addition, the moderating effect of industry type is also investigated. Theoretical and managerial implications are discussed at the end.
\end{abstract}

References available upon request.

\footnotetext{
X. Liu $(\bowtie)$

Rowan University, Glassboro, NJ, USA

e-mail: liul@rowan.edu
} 